\title{
HAY-PLASTIC COMPOSITES - EFFECT OF HAY PARTICLE SIZE ON THE WATER ABSORPTION
}

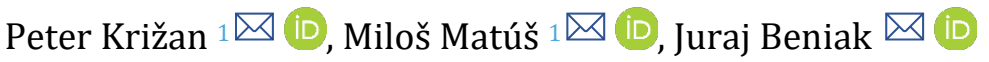 \\ ${ }^{1}$ Institute of Manufacturing Systems, Environmental Technology and Quality Management, Faculty of \\ Mechanical Engineering, Slovak University of Technology in Bratislava, Slovak Republic.
}

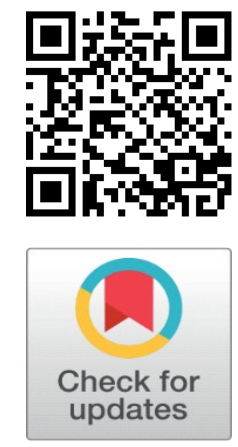

Received 2 November 2021

Accepted 14 December 2021

Published 31 December 2021

\section{CorrespondingAuthor}

Peter Križan,

peter.krizan@stuba.sk

DOI

10.29121/granthaalayah.v9.i12.2021 .4445

Funding: This research received no specific grant from any funding agency in the public, commercial, or not-for-profit sectors.

Copyright: (C) 2021 The Author(s). This is an open access article distributed under the terms of the Creative Commons Attribution License, which permits unrestricted use, distribution, and reproduction in any medium, provided the original author and source are credited.

\section{ABSTRACT}

This paper presents the results of experimental investigations into the effects of raw material composition and properties on water absorption in hay-plastic composites. It is possible to identify important parameters of the raw materials used in HPCs production such as the size of the hay sawdust particles, hay/plastic ratio, and type or plastic matrix. The goal of this research was to produce HPCs with acceptable and comparable quality. This is determined by the final mechanical properties. The particle size of the hay sawdust used to produce HPC has a significant impact on the mechanical properties of composites as well as other important properties like water absorption, hardness and frost resistance. This paper examines the relationship and impact of the input haysawdust particle sizes, hay/plastic ratio, and water absorption on composites. The authors also intend to explore the potential for waste materials usage. These experimental research results were made using a semi-operational molding press, where injection is done by a screw. Meadow hay, HDPE resin matrix, and recycled HDPE were used as input materials. The lids made from PET bottles served as the containers. Based on a combination of default levels of hay/HDPE concentration and using recycled HDPE rather than virgin HDPE, the effect of hay sawdust particles on water absorption was determined.

Keywords: Hay Sawdust, HPC, Hay-Plastic Composites, Particle Size, Water Absorption, Recycling

\section{INTRODUCTION}

To improve the physical and mechanical properties of products made from biomass-plastic composites, fillers are used. Today, environmental protection is a major concern. This is why there is increasing interest in organic fillers such as wood, straw, corn stalks, or rice husks replacing inorganic fillers. Due to their easy recycling and ecological benefits, the development of renewable raw materials composites has been a major success. Natural fibers can be easily recycled, are carbon dioxide neutral, and are readily available in large quantities Migneault et al. (2009), Kuo et al. (2009) The scope of use of biomass-plastic composites (BPCs) today is mainly in the automotive, engineering and electrical engineering industries. There are also various research studies Zhang et al. (2008),Yang et al. (2007),Smith and Wolcott (2006) that examine the effects of material and technological variables on production. BPCs can be made by mixing ground biomass particles with heated thermoplastic resin Soury et al. (2009),Yam et al. (1990), Carrino et al. (2011). Although extruding the material 
in the desired form using injection molding or extrusion is the most popular method of production, composites can also be made using additive manufacturing resp. 3D printing. BPCs can be made from many virgin thermoplastics, but the most popular is polyethylene-based BPCs Soury et al. (2009). BPCs made from virgin materials typically contain 60-65\% high-density plasticethylene (HDPE), $30 \%$ biomass particles with defined granulometry Soury et al. (2009), Godard et al. (2009) and the additions are determined according to the final use. This allows the product to be tailored to the intended application area Smith and Wolcott (2006).

This area faces major challenges. The research results can be extremely useful in HPCs production. They have shown that it is possible to use waste materials for HPC products. This could also allow for rapid prototyping. This is a very important issue. The main focus of this research is to determine the effect of material variables on the mechanical properties of HPCs made from waste raw materials. Based on previous research and analyses of research findings Kuo et al. (2009),Zhang et al. (2008),Soury et al. (2009),Yam et al. (1990) ,Sviatskii et al. (2019) and knowledge, important input variables, such as type of raw material, and size of hay sawdust particles, can be identified during the production process of HPCs Migneault et al. (2009).Kuo et al. (2009) The quality indicators can show their impact on the mechanical properties of HPCs (ultimate strength, maximum force, impact strength, toughness, modulus of elasticity, water absorption, hardness, etc.). Yang et al. (2007).Soury et al. (2009),Sviatskii et al. (2019) The most important role of biomass particle size in this instance is the hay sawdust.

The use of recycled or waste materials to produce BPCs is another issue Yam et al. (1990) . The European economy is dependent on raw materials. They are a solid industrial base that produces a broad range of products and applications for modern life. Unrestricted and reliable access to certain raw material is a growing concern within the EU and globally. Given the continuing strategic importance of raw materials for the EU industry, the Commission is currently implementing a wide range of measures under the EU Raw Materials Initiative to contribute to a secure, sustainable and affordable supply of raw materials Bobba et al. (2020). One of the possibilities for the production companies to ensure the EU strategic plan is implementation of the circular economy. The circular economy (also known as "green economy") is an economic model that is completely different from the current one - the linear Olabarria et al. (2019). The profit margin of the current "take-produce-throw away" system is primarily due to the excessive consumption of non-renewable and renewable raw materials. This is logically incompatible with long-term sustainability. The current system is unsustainable if we consider other factors such as low-cost labor from developing countries, rising consumption, and the negative impact of human activity on the environment Olabarria et al. (2019). The current system is unsustainable economically, ecologically, and socially. The circular model, on the other hand, is designed to increase the competitiveness of countries and ensure stable economic growth. It also helps maintain a healthy environment. The circular economy yields by efficient use of natural resources, which is achieved through the efficient recovery and reuse of materials, products, and components. The material flow is closed by their constant return to the technical or biological cycle. This drastically reduces waste, the cost of material inputs, and the energy required to produce new products. This concept focuses on the use of renewable energy, eco-innovation and rental, sharing, or support for local trade. There is a growing concern about environmental issues, and a need for more polymer-based products, which has led to increased interest in polymer composites-based materials Križan et al. (2020). The EU's largest waste stream is construction waste. The EC Waste Directive 2008/98 aims to create a more sustainable construction sector by recovering $70 \%$ of non-hazardous 
construction materials by 2020 Križan et al. (2016). To achieve this goal, it is necessary to find new ways to maximize material recovery.

The general purpose of this paper is to present the research findings regarding the effect of particle size and percentage amount of hay sawdust in composites on the water absorption of hay-plastic composites. Authors would like to present this effect also in case of HPCs based virgin thermoplastic and also in case of HPCs based waste raw materials. Such of results are very important and interesting from the production possibilities and applications of HPCs based waste raw materials point of view. Future research results can be extremely helpful in HPCs production with 3D printers. They also show the possibility of using waste materials for HPC products and increase the environment's responsibility.

\section{MATERIALS AND METHODS}

Our experiment aims to investigate the effects of raw material properties (particle sizes of hay sawdust on water absorption in hay-plastic composites). The basic raw materials needed to be prepared in order to determine this effect. HDPE (high density polyethylene, named TIPELIN 1108J from the Slovak company Slovnaft a.s. Bratislava), with the melt index of $8.0 \mathrm{~g} / 10$ minutes), HDPE rec. These plastic matrices were made from recycled high-density, high-density polyethylene that was derived from PET bottles' lids. A South Slovakian agricultural company provided the Meadow Hay sawdust. This kind of agricultural crop is a typical crop in Slovakia and are widely and usually cultivated in our country. Samples of meadow hay in the untreated form were obtained from an agricultural company. For processing the hay to the form of hay sawdust the hammer mill STOZA ŠV5 equipped with screen $8.0 \mathrm{~mm}$ and $4.0 \mathrm{~mm}$ in diameter was used. On Figure 1 can be seen the achieved samples of hay sawdust after shredding.

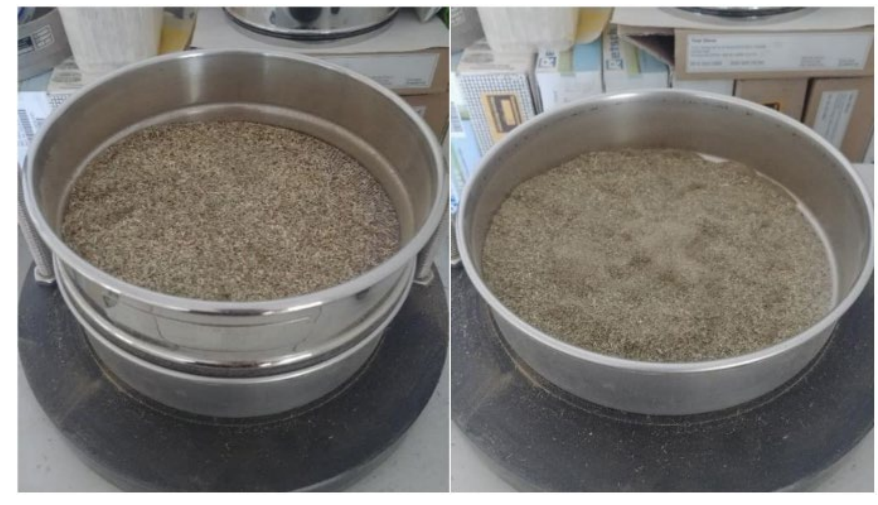

Figure 1 Shredding of hay to the samples of hay sawdust - with particles up to $0.5 \mathrm{~mm}$ (left), with particles up to $1.0 \mathrm{~mm}$ (right)

Shredding on two levels was used, for obtaining proper number of samples with suitable level of fineness. Retsch Vibrating Sieve Equipment AS 200 was initially used, in accordance with EN ISO 17827-1 Križan et al. (2020), to analyze the distribution of particle sizes (Figure 2) was used. Figure 2 illustrates the distribution of raw material particles.

Our case involved the determination of the interaction between water absorption in HPC's samples, type and concentration of plastic matrix used in HPCs, hay/plastic ratio, and the particle size of hay used in HPCs [15]Križan et al. (2016). The experimental research was conducted according to the plan Križan et al. (2017). Three influencing parameters were used in experimental research: the 
type of polymer matrix, the particle size, and the concentration ratio of plastic/hay (see Table 1).

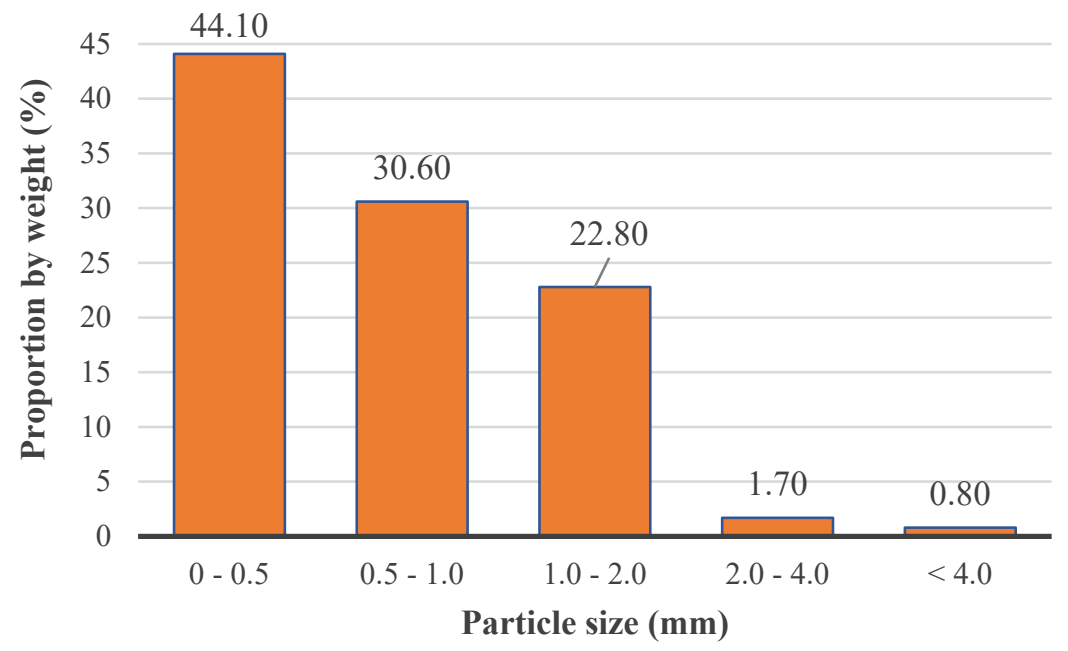

Figure 2 Raw material particle size distribution of the samples studied

Table 1 Input controllable variables of the experiment Bobba et al. (2020)

Variables

\begin{tabular}{cccc} 
Levels & Hay/Plastic ratio (\%) & Particle size (mm) & Polymer matrix type (-) \\
1 & $0 / 100$ & $0-0.5$ & HDPE \\
2 & Oct-90 & $0.5-1.0$ & HDPE rec. \\
3 & $20 / 80$ & $\operatorname{mix}$ & - \\
4 & $30 / 70$ & - & - \\
\hline
\end{tabular}

The experimental research was conducted with raw materials. Hay for the experiment was treated accordingly. The following processes were used to obtain the hay particle sizes. We know that only particles with a particle size of 0-0.5 mm, 0.5-1.0mm, and "mix" are acceptable Križan et al. (2016), Standard (2016) This particle size was called "mix", and it contained $50 \%$ of particles between 0 and 0.5 $\mathrm{mm}$, and $50 \%$ of particles between 0.5 to $1.0 \mathrm{~mm}$. SPCs are rarely made from larger particles. This experiment used meadow hay sawdust of up to $0.5 \mathrm{~mm}$ in size and up to $1.0 \mathrm{~mm}$ in particle size (Figure 1), with the properties shown in Figure 2. Kern MRS120-3 balance was used to measure the moisture content of selected hay prior to extrusion, mixing, and injection. The Kern MRS 120-3 balance was used to measure the moisture content of the raw feedstock. It was heated at $105 \pm 2{ }^{\circ} \mathrm{C}$ for approximately 30 minutes until it reached a constant weight Standard (2016). Preparation of the moisture content of hay sawdust at a level of 1.7 percent was done. A Retsch SM300 was used as a cutting mill (Figure 3). According to the experimental plan in Table 2 , a set number of samples will be made for testing.

The used injection mould is made according to ISO 527-2/ 1A/ 10. It's used for injection of normalized-tensile specimens Standard (1997). See Figure 4. Each set was produced according to the experimental plan. During injection, the operating parameters of the injection press were recorded. 

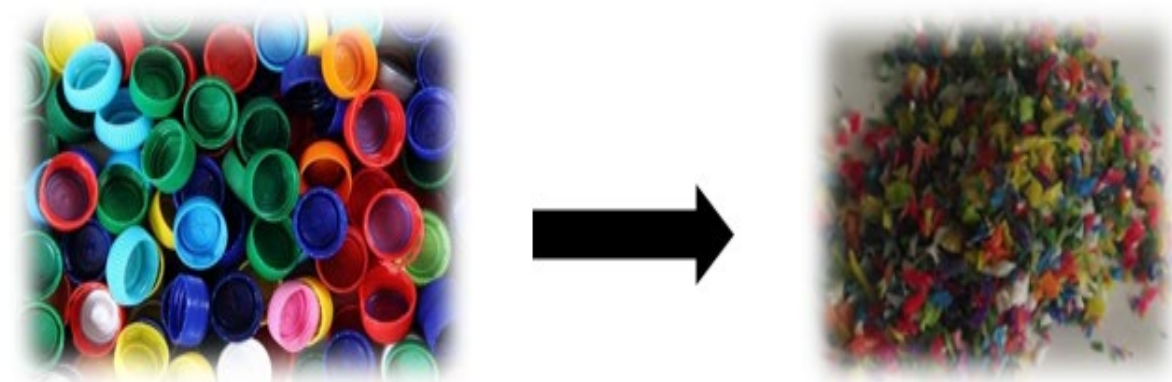

Figure 3 The disintegration of PET bottle lids

To ensure that specimens are produced to the expected quality, and to prevent the formation of bubbles and the collapsing of the specimen sides, the operating parameters of the injection process were adjusted to meet the requirements of proper filling of the form.

Table 2 Designed composition of experimental research Standard (2016)

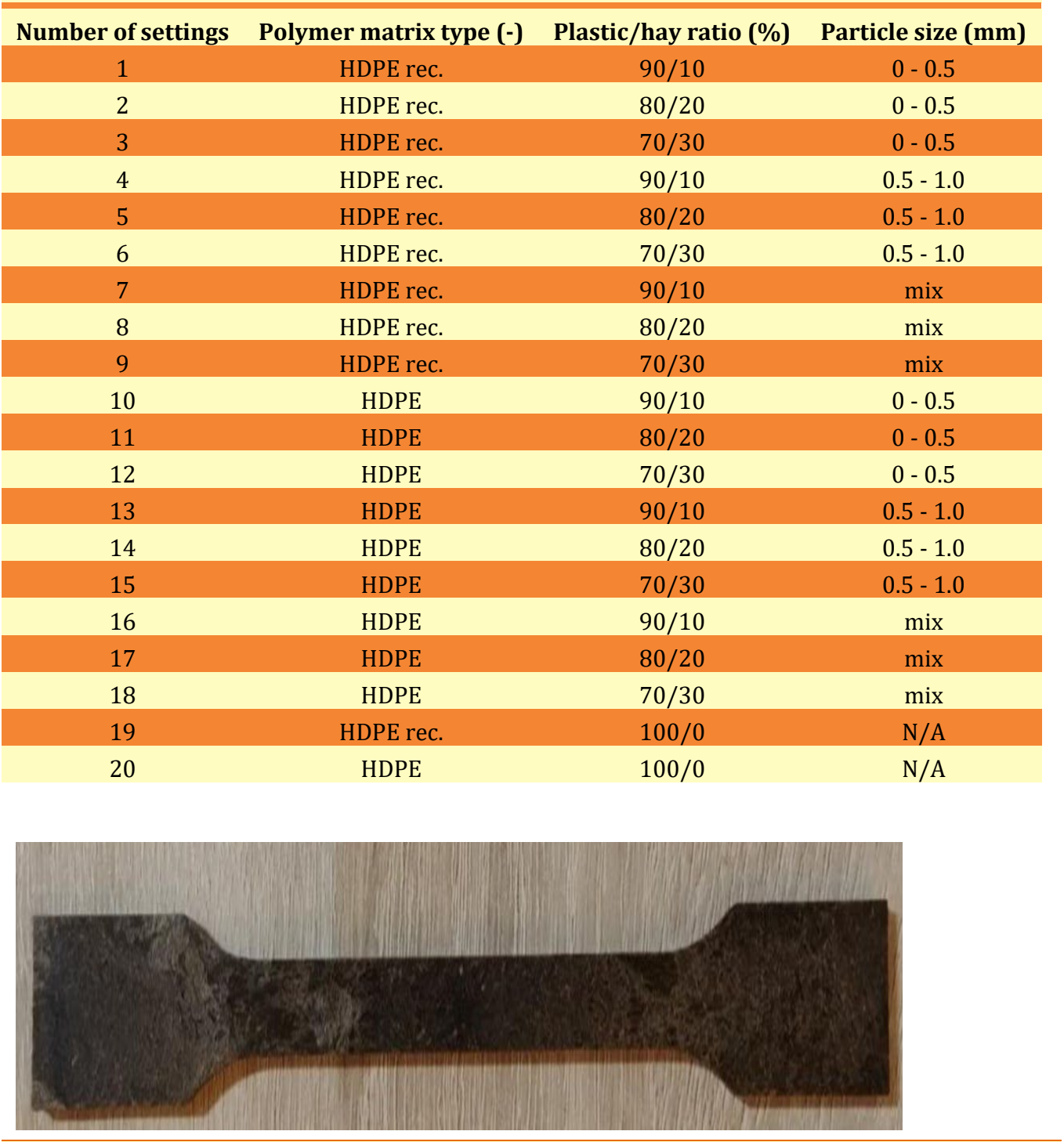

Figure 4 Testing specimen for tensile test after injection 
Figure 5. shows the hay/plastic ratios needed to be mixed with an electric mixer. Weight was managed by using MR120 balance. The composites granules were injected by twin-screw extruder LTE26. Final specimens were made by Mitsubishi 180 MEt III injection molding machine Chung (2010). Specimens sized to correspond with the Standard STN EN ISO 527-3 specifications were produced.
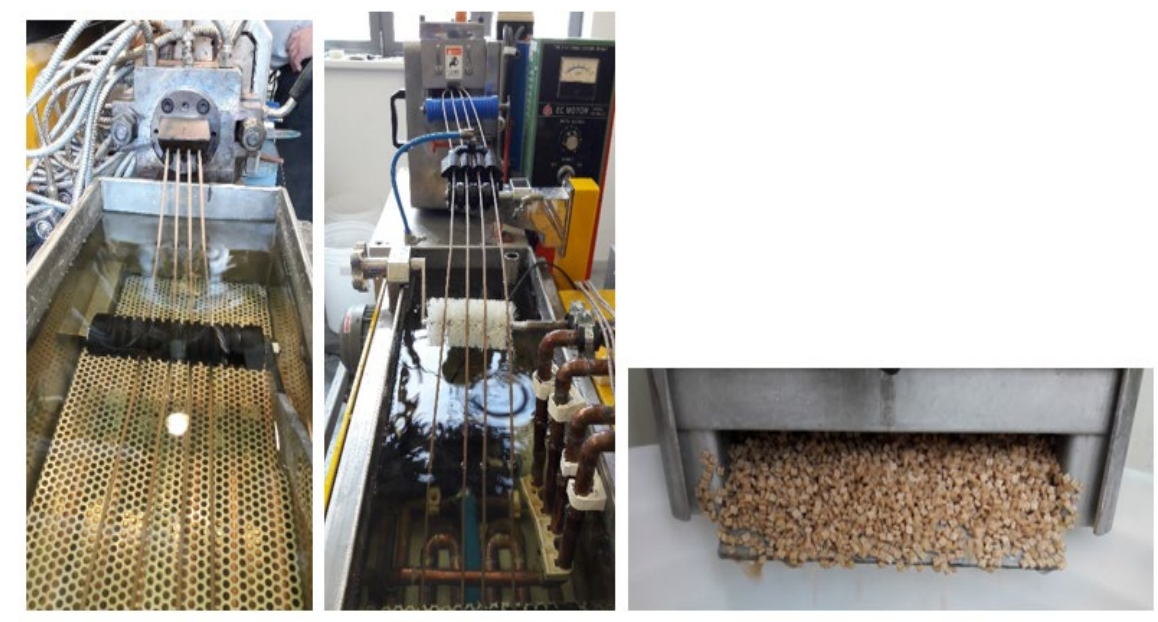

Figure 5 Extrusion and production of composites strings by twin-screw extruder and composites granules by cylindrical shredder

As was mentioned above, for each setting according to the experimental plan (Table 2) a specific number of specimens (Figure 4) were produced. The Figure 4 shows specimen used for the tensile test. This is where a sample is placed under controlled tension until it fails. We will use specimens for the tensile test to determine the effects of particle size and water absorption on the HPCs density. Hayplastic composites can absorb different amounts of water and thus its presence can significantly affect material properties such as electrical insulation resistance, mechanical properties, dielectric loss, dimensions or density. The absorbency of hay-plastic composites is influenced by the final composition of the material Messiry and Deeb (2016),Thakur et al. (2017) Therefore, the following determination methodology of water absorption was used. The HPC specimens were immersed in distilled water and thus exposed to high humidity. Percentage weight gain during immersion was measured by Kern MR 120 digital balance and was calculated by following equation (1) Messiry and Deeb (2016), Thakur et al. (2017):

water absorption $=\frac{\text { specimen weight in time }- \text { initial weigth of specimen }}{\text { initial weigth of specimen }} .100(\%)$

For the determination of HPCs density the digital caliper Mitutoyo 500-196-20 when the length, width and thickness of specimen was measured. These values for the calculation of specimen's volume were used and within the weight of specimens the densities were calculated. 


\section{RESULTS AND DISCUSSIONS}

According to the experimental plan (Table 2), testing specimens were produced. Determination of density with specimens shown in Figure 4 was provided. On the following Figure 6 can be seen the effect of hay particle size in combination with plastic/hay ratio on the composite's density. This figure shown this effect at composites produced from the virgin HDPE matrix and also from the recycled HDPE. We can see that in all settings, composites based recycled HDPE has higher density values. This is caused by using of unspecified sample of lids from PET bottles. In general, the differences are not so high, the average density difference is on a $0.81 \%$ level. When we look closer on the effect of hay particle size on the density, we can see that the composites containing smaller particles $(0-0.5 \mathrm{~mm})$ have higher densities comparing the composites containing higher particles $(0.5-$ $1.0 \mathrm{~mm}$ ). This is a logical output because smaller particles have higher compressibility and during the injection process is possible produce composites with the higher density. This finding is valid above the $80 / 20 \%$ plastic/hay ratio. Densities of composites containing "mix" very well represents the ratio 50/50\% divided to both remaining particle sizes.

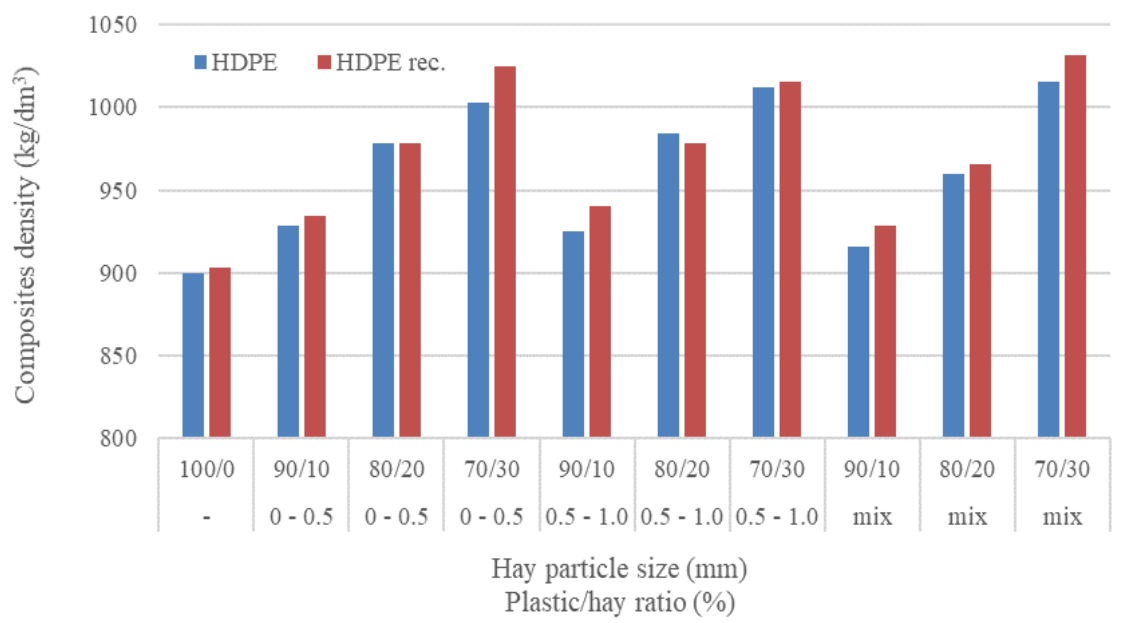

Figure 6 Effect of hay particle size in combination with plastic/hay ratio on the composite's density

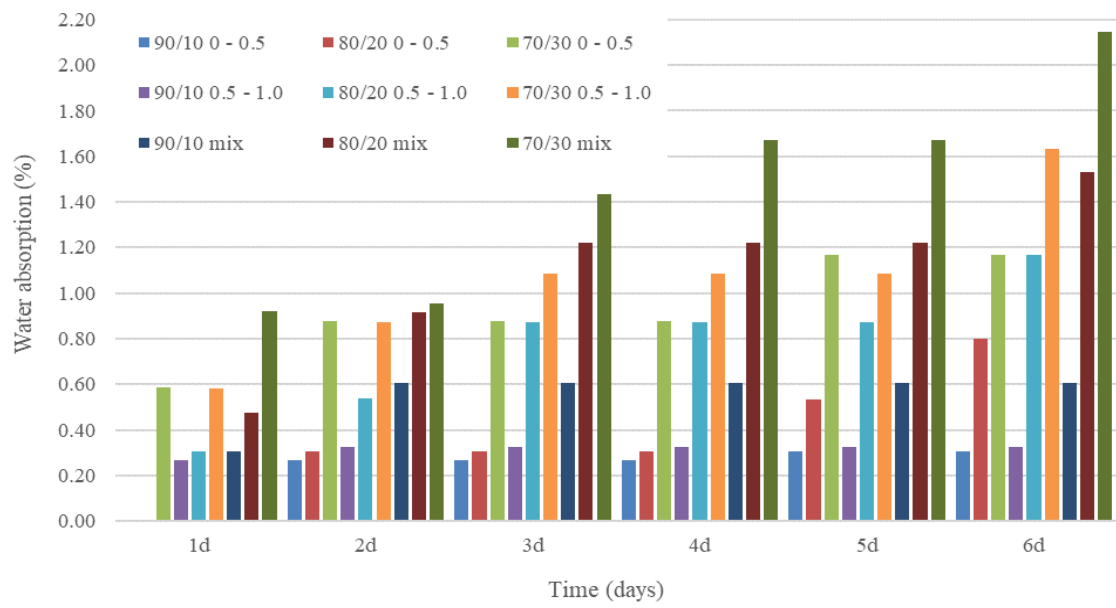

Figure 7 Dependence of water absorption on composite's immersion time (composites-based virgin HDPE) 
On Figure 7, the dependence of water absorption on composite's immersion time is displayed. Here the results intended to a composites-based virgin HDPE are presented.

Figure 8 shown the dependence of water absorption on composite's immersion time, where the composites based virhin HDPE containing particle size $0-0.5 \mathrm{~mm}$ are compared. The highest water absorption at composites produced from 70/30 plastic/hay ratio was determined. We can see that with higher percentage of hay sawdust in composites also increases the water absorption within the immersion time. The step changes can be seen, where the composites with different hay sawdust percentage absorbed water stepwise, e.g., absorption value in $\%$ after several days was changed.

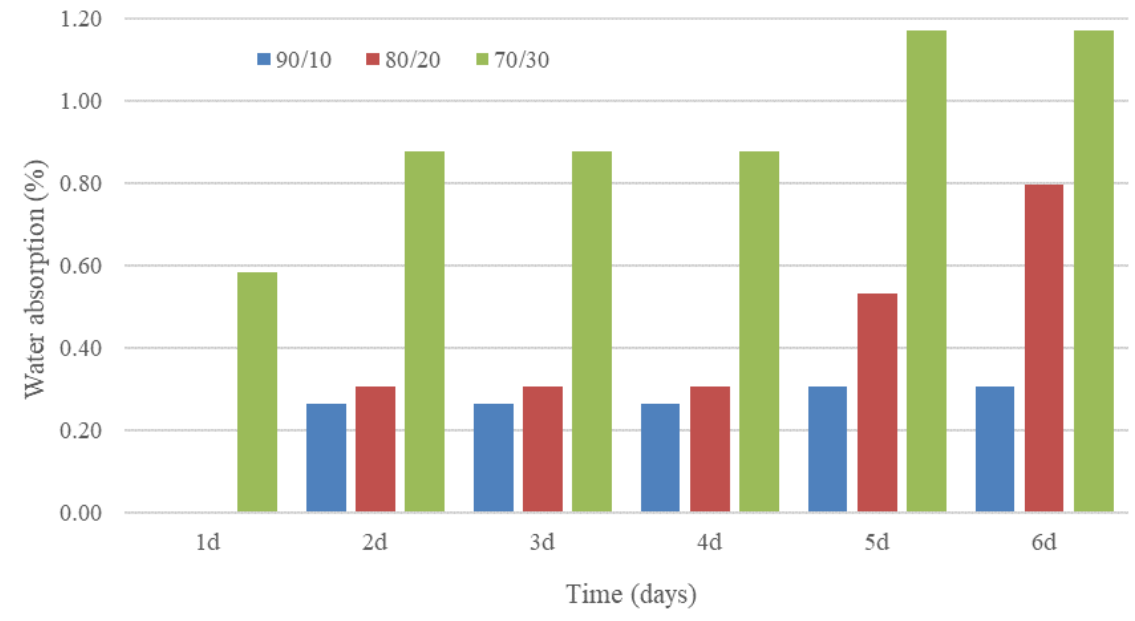

Figure 8 Dependence of water absorption on composite's immersion time (composites-based virgin HDPE, particle size $0-0.5 \mathrm{~mm}$ )

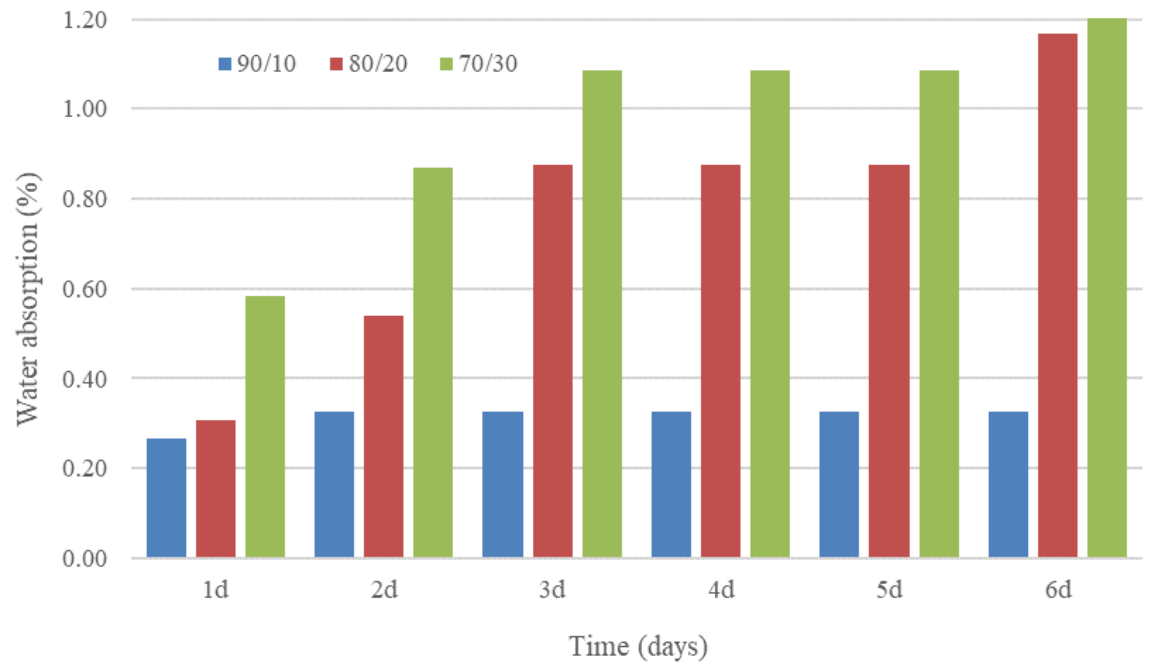

Figure 9 Dependence of water absorption on composite's immersion time (composites-based virgin HDPE, particle size $0.5-1.0 \mathrm{~mm}$ )

Figure 9 shown the dependence of water absorption on composite's immersion time, where the composites-based virgin HDPE with particle size $0.5-1.0 \mathrm{~mm}$ are compared. Here the situation is a little bit different. In general, the water absorption 
with higher percentage values were determined, and also the composites absorbed the water faster than composites from $0-0.5 \mathrm{~mm}$ particle size. Bigger hay particles influence the bindings creation during composites production and thus also the water absorption.

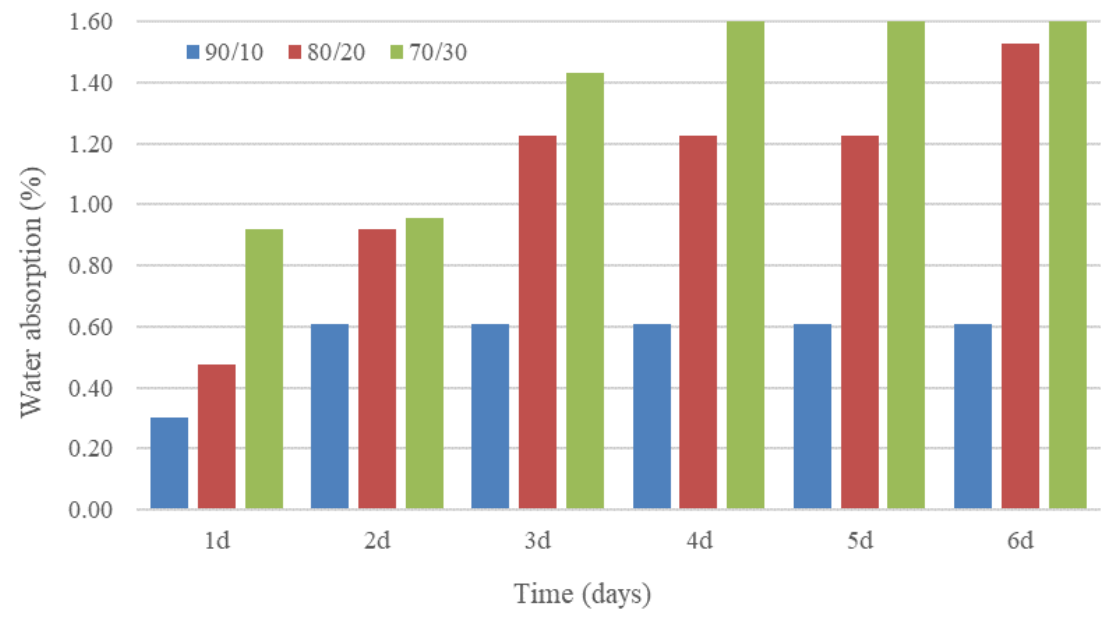

Figure 10 Dependence of water absorption on composite's immersion time (composites-based virgin HDPE, mix particle size)

Figure 10, the dependence of water absorption on composite's immersion time is displayed, where the composites-based virgin HDPE with mix particle sizes. Here the situation is very similar than above. The higher percentage of the water absorption values were determined, and also the composites absorbed the water faster than composites from $0-0.5 \mathrm{~mm}$ and 0.5-1.0 particle size.

On Figure 11, 12, 13 and 14, the dependence of water absorption on composite's immersion time is also displayed. But here the composites based recycled HDPE are presented. Figure 11 shown whole state with all possible combination of particle sizes and plastic/hay ratios. Figure 12, 13 and 14 displayed separately the composites with hay particle size $0-0.5 \mathrm{~mm}$, composites with hay particle size $0.5-1.0 \mathrm{~mm}$ and composites with mix particle size, within the plastic/hay ratio. The fact with the highest water absorption at composites produced from hay particles at $70 / 30$ plastic/hay ratio was proven also here. We can see that with increasing percentage of hay sawdust also increases the water absorption of composites. The general trend in hay particle's effect on water absorption is the same. We can see that with higher percentage of hay sawdust in composites also increases the water absorption within the immersion time. But the effect of the particle size on water absorption is little bit different. Instead of mix particle size, we can say that water absorption is not influenced significantly by increasing of particle size. With increasing the particle size also increases the water absorption, but very slightly. Also, the effect of monitored variables on absorption speed was determined. Both variables' changes, the particle size and plastic/hay ratio, influencing the absorption speed. 


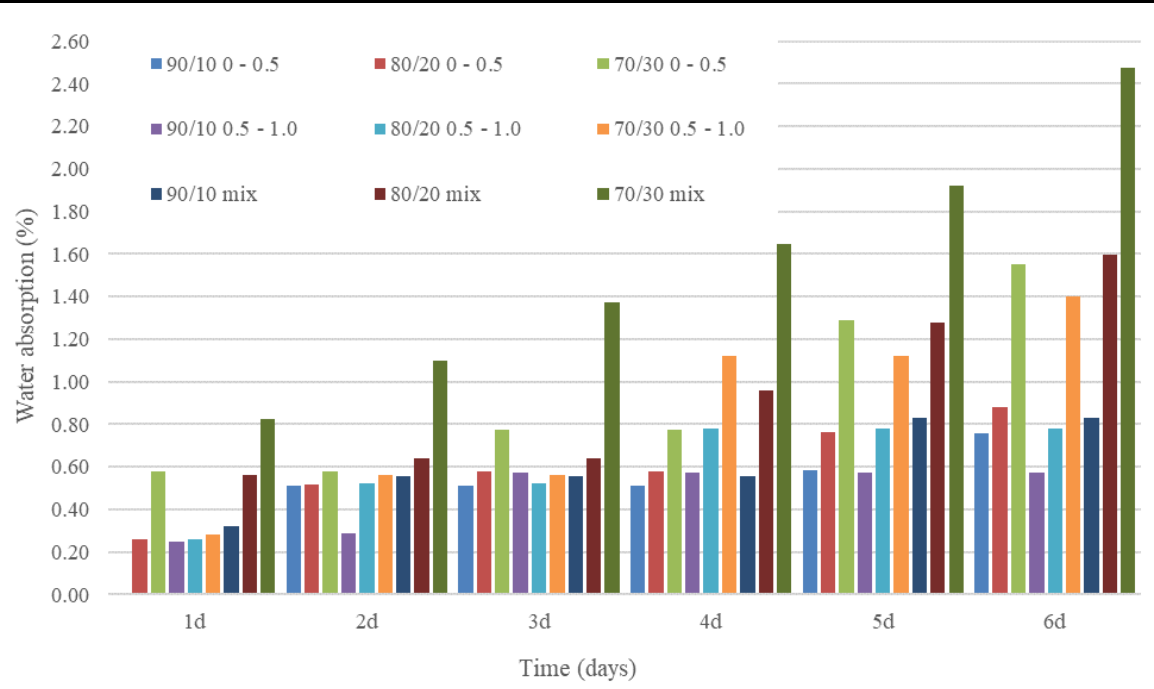

Figure 11 Dependence of water absorption on composite's immersion time (composites based recycled HDPE)

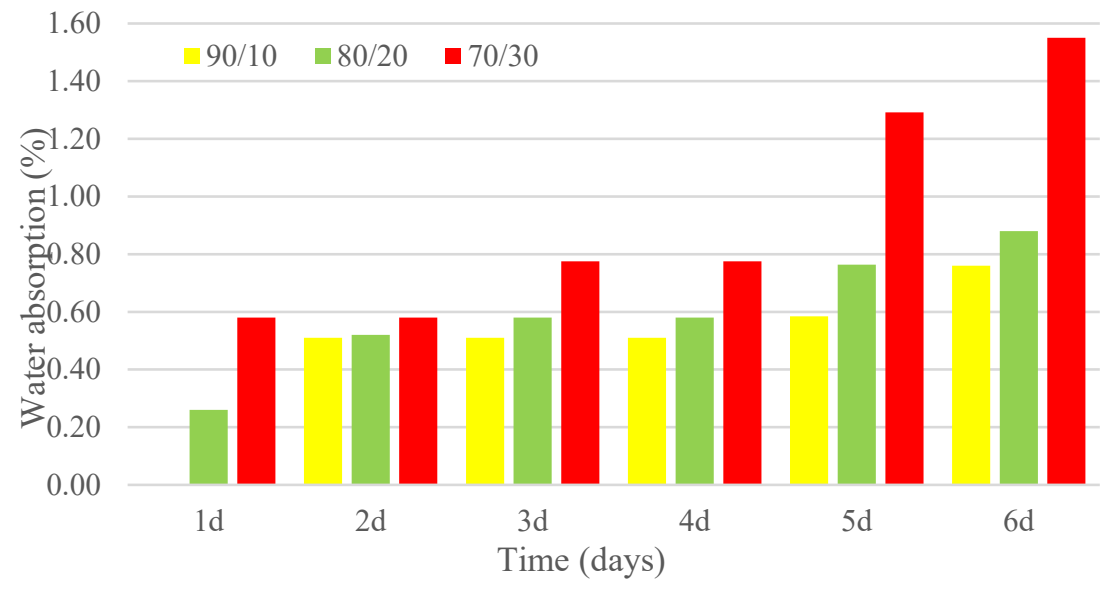

Figure 12 Dependence of water absorption on composite's immersion time (composites based recycled HDPE, particle size $0-0.5 \mathrm{~mm}$ )

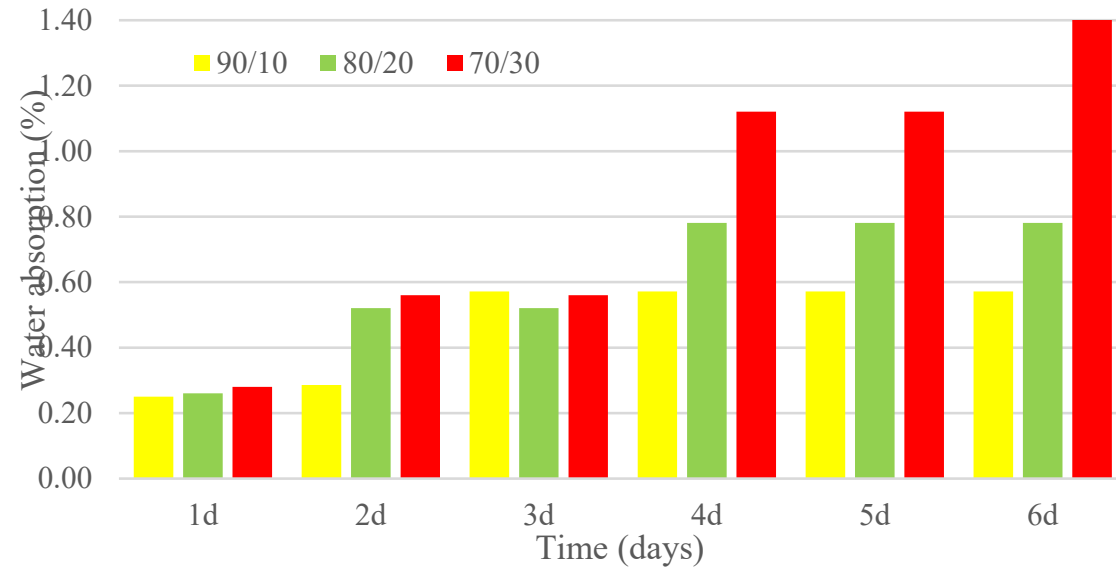

Figure 13 Dependence of water absorption on composite's immersion time (composites based recycled HDPE, particle size $0.5-1.0 \mathrm{~mm}$ ) 


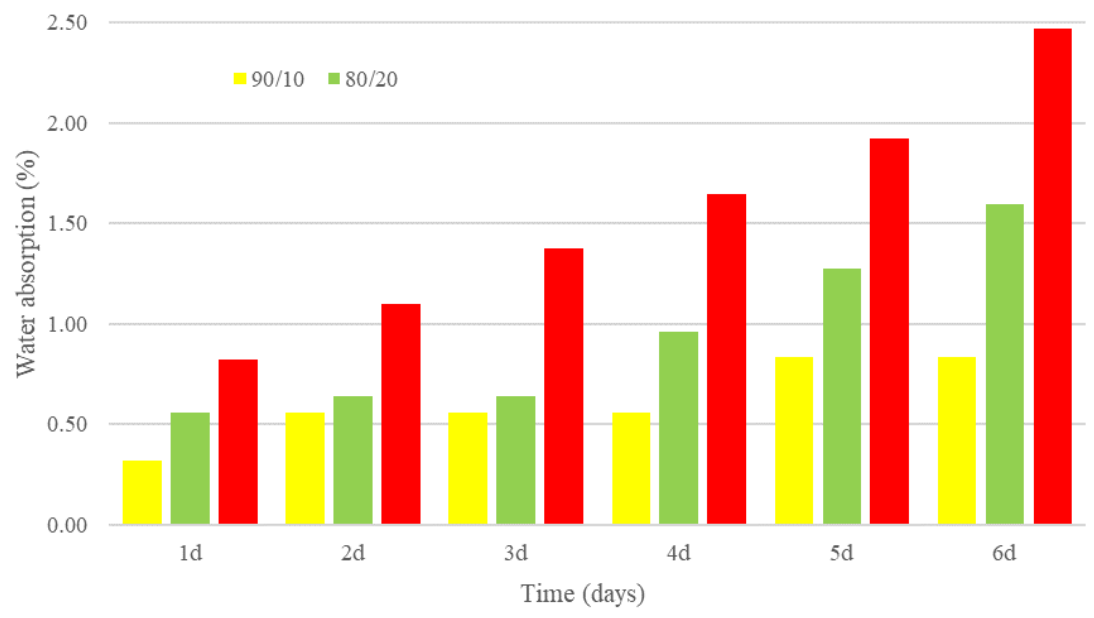

Figure 14 Dependence of water absorption on composite's immersion time (composites based recycled HDPE, mix particle size)

According to the general comparison, the recycled HDPE seems less appropriate than virgin HDPE from water absorption point of view. When comparing particle sizes on a 0-0.5 $\mathrm{mm}$ level within the plastic/hay ratios, composites based recycled HDPE showed higher water absorption. But when comparing bigger particle sizes, composites based recycled HDPE showed lower water absorption.

On the other hand, the differences are not so significant, and this can be positive research finding from the environmental point of view. Whereas composites are mostly used for outdoor applications, water absorption is a very important behavior, even if we can reduce the wastes and thus use such a material as a recycled product. Moreover, if we can reach better results with recycled wastes with lower treatment costs.

\section{CONCLUSIONS AND RECOMMENDATIONS}

This research focused on plastic and hay raw material recovery. The preliminary phase results are presented on the effects of hay sawdust size and properties on water absorption by the HPCs. Also, the effect of composites using different plastic matrix and different hay/plastic ratio.

The main conclusions that can be withdrawn from this study are as follows:

- HDPE recycled originating from PET bottle lids can be used for composites production,

- Composites based HDPE recycled had higher water absorption than composites-based virgin HDPE, it depends on particle size used,

- Composites based virgin HDPE had faster water absorption than composites based recycled HDPE,

- Hay/plastic ratio affects the water absorption, with increasing of this ratio, e.g., with increasing amount of hay sawdust in composites also increases the water absorption, within both plastic matrixes,

- Hay sawdust particle size affects the water absorption, it depends also on hay/plastic ratio. 
The second phase of the experimental research will be focused on plastic and hay raw materials recovery using rapid prototyping technology. It is a very interesting and ambitious issue to research the basic composition of materials suitable for 3D printing.

\section{ACKNOWLEDGEMENTS}

The paper is a part of the research done within the project APVV-18-0527 "Development and optimization of additive manufacturing technology and design of device for production of components with optimized strength and production costs" funded by the Slovak Research and Development Agency, and the project VEGA $1 / 0665 / 21$,Research and optimization of technological parameters of progressive additive manufacturing of effective protective equipment against COVID-19" funded by the Ministry of Education of Slovak Republic and to the Slovak Academy of Sciences.

\section{REFERENCES}

Bobba S, Carrara S, Huisman J, Matheiux F, Pacel C, et al. (2020) Critical Raw Materials for Strategic technologies and Sectors in the EU, A Foresight Study, Luxembourg, European Union.

Carrino L, Ciliberto S, Giorleo G, Prisco U. (2011) Effect of filler content and temperature on steady-state shear flow of wood/high density polyethylene composites, Polymer Composites. ; 5 : 796 - 809. Retrieved from https://doi.org/10.1002/pc.21101

Chung D. (2010) Composite Materials : Science and Applications, 2. ed., Springer, London, UK.

El Messiry M, El Deeb R. (2016) Analysis of the wheat straw/flax fiber reinforced polymer hybrid composites, J. App. Mech. Eng, ; 5 : 1-5.

Godard F, Vincent M, Agassant JF, Vergnes B. (2009) Rheological behavior and mechanical properties of sawdust/polyethylene composites, Journal of Applied Polymer Science. ; 4 : 2559 - 2566. Retrieved from https://doi.org/10.1002/app.29847

Križan P, Beniak J, Matúš M, Šooš L', Kolláth L'. (2017) Research of plastic and wood raw wastes recovery, Advances Materials Letters. ; 8 : 983-986. Retrieved from https://doi.org/10.5185/amlett.2017.1587

Križan P, Beniak J, Šooš L', Kolláth L', Matúš M. (2016) Experimental research of mechanical properties and parameters of waste raw materials based woodplastic composites, in : American Advanced Materials Congress: Proceedings and abstracts book. Miami, USA.

Križan P, Bábics J, Beniak J, Matúš M. (2020) Influence of raw material properties on parameters of injection press during the injection of composites based biomass and plastic waste, In Novel Trends in Production Devices and Systems VI. (NTPDS VI.), 1st Ed. Zürich, Trans Tech Publications. ; 152-161. Retrieved from https://doi.org/10.4028/www.scientific.net/MSF.994.152

Kuo P, Wang S, Chen J, Hsueh H, Tsai M. (2009) Effects of materials compositions on the mechanical properties of wood-plastic composites manufactured by injection molding, J. Mat. D. ; 30 : 3489-3496. Retrieved from https://doi.org/10.1016/j.matdes.2009.03.012

Migneault S, Koubaa A, Erchiqui F, Chaala A, Englund K, Wolcott MP. (2009) Effects of processing method and fiber size on the structure and properties of wood- 
plastic composites, J. Comp. : Part A. ; 40 : 80-85. Retrieved from https://doi.org/10.1016/j.compositesa.2008.10.004

Olabarria M, Vella K, Reines R, Gontarz A, et al. (2019) The European Machine Tool Sector and the Circular Economy, CECIMO Circular.

Smith PM, Wolcott MP. (2006) Opportunities for wood/natural fiber-plastic composites in residential and industrial applications, Forest Products Journal. ; $3: 21$ - 27.

Soury E, Behravesh AH, Rouhani Esfahani E, Zolfaghari A. (2009) Design, optimization and manufacturing of wood-plastic composite pallet, Material \& Design. ; 10 : 4183 - 4191. Retrieved from https://doi.org/10.1016/j.matdes.2009.04.035

Standard EN ISO 17827-2, (2016) Solid biofuels. Determination of particle size distribution. Part 2 : Vibrating screen method using sieve apertures of 3,15 $\mathrm{mm}$ and below. European Committee for Standardization, Brussels, Belgium.

Standard EN ISO 18134-2, (2016) Solid biofuels. Determination of moisture content. Oven dry method. Part 2 : Total moisture. Simplified method, European Committee for Standardization, Brussels, Belgium.

Standard STN EN ISO 527-3, (1997) Plastics. Determination of Tensile Properties. Part 3 : Test Conditions for Films and Sheets, Bratislava, Slovakia.

Sviatskii V, Mudriková A, Holubek R., Horník J, Sokolov M. (2019) The design of melting units for production of synthetic fibrous materials by vertical blowing method from PET raw materials, Material Science Forum. ; 952 : 216-222. Retrieved from https://doi.org/10.4028/www.scientific.net/MSF.952.216

Thakur VK, Thakur MK, Kessler MR. (2017) Handbook of composites from renewable materials, design and manufacturing, Scrivener publishers, Wiley, USA. Retrieved from https://doi.org/10.1002/9781119441632

Yam KL, Gogoi BK, Lai ChC, Selke SE. (1990) Composites from compounding wood fibers with recycled high density polyethylene, Polymer Engineering and Science. ; 11 : 693 - 699. Retrieved from https://doi.org/10.1002/pen.760301109

Yam KL, Gogoi BK, Lai ChC, Selke SE. (1990) Composites from compounding wood fibers with recycled high density polyethylene, Polymer Engineering and Science. ; 11 : 693 - 699. Retrieved from https://doi.org/10.1002/pen.760301109

Yang HS, Wolcott MP, Kim HS, Kim S, Kim HJ. (2007) Effect of different compatibilizing agents on the mechanical properties of lignocellulosic material filled polyethylene bio-composites, Composite Structures. ; 3 : 369 - 375. Retrieved from https://doi.org/10.1016/j.compstruct.2006.02.016

Zhang Y, Zhang SY, Choi P. (2008) Effects of wood fiber content and coupling agent content on tensile properties of wood fiber polyethylene composites, Holz als Roh- und Werkstoff. ; 4 : 267 - 274. Retrieved from https://doi.org/10.1007/s00107-008-0246-4 